\title{
Evaluation of the frontal sinuses dimensions in sex estimation among a sample of adult Kashmiri population using multidetector computed tomography
}

\author{
Altaf Hussain Chalkoo ${ }^{1}$, Prenika Sharma ${ }^{2, *}$, Nusrat Nazir ${ }^{3}$, Saima Tariq ${ }^{4}$ \\ ${ }^{1}$ Professor and HOD, ${ }^{2}$ Post Graduate Student, ${ }^{3}$ Senior Resident, ${ }^{4}$ Post MDS, Dept. of Oral Medicine and Radiology, Government Dental \\ College Srinagar, Jammu and Kashmir, India \\ *Corresponding Author: Prenika Sharma \\ Email: prenikasharma19@gmail.com
}

\begin{abstract}
Introduction: Aim of the present study is to determine gender using morphometric measurements on the frontal sinuses MDCT- scan. Materials and Methods: The study included 100 subjects (50 males and 50 females). For each participant frontal sinus dimensions were measured for both sides using MDCT on commercially available software.

Results: The mean lengths of Right width, Left width, Left depth and Left height were significantly larger in males than in females. There was no significant difference in measurements of both sides in either males or females.

Conclusion: Some parameters in frontal sinuses were significantly larger in males and these can be used in forensic for determination of gender. Sample size was small so study with larger sample size is advised in future.
\end{abstract}

Keywords: Frontal sinus, Morphometric analysis, Sex, Computed tomography, MDCT, CT.

\section{Introduction}

Estimation of sex is more reliable if the complete skeleton is available for analysis but in forensic cases human skeletal remains are often incomplete or damaged. ${ }^{1}$ Sex is considered as one of the "big four" parameters in forensic identification besides, race, age, and stature. Accurate sexing of human remains provides valuable clues to a forensic scientist and primarily narrows down the pool of possible victim matches. ${ }^{2}$ Skeletal remains have been used for sexing the individual as bones of the body are last to perish after death, next to enamel of teeth. ${ }^{3}$

Sex can likewise be determined from various bones/ skeletal remains. When whole skeleton is available, the sex can be determined with almost $99-100 \%$ accuracy. Among individual bones, pelvis is known to provide the most accurate results in the determination of sex (95\% accuracy), followed by skull (92\% accuracy). ${ }^{4}$

Radiography was used as forensic tool for identification of human, especially in cases where the body is decomposed, fragmented, or burned. Images can assist in measuring accurate dimensions for which certain formulae can be applied for sex determination (Kiruba et al., 2014). ${ }^{5}$ Computerized Tomography (CT) is considered an excellent imaging technique and is the modality of choice for the evaluation of Paranasal sinuses and craniofacial bones where precise measurement of Paranasal sinuses dimensions could be provided. ${ }^{6}$

Morphological features depicted on the radiographs must meet the following two requirements in order to be of forensic identification value: First, the feature has to be unique to the individual; second, it has to remain stable over time despite the ongoing life processes. Both these criteria are fulfilled by the frontal sinuses. Turner and Porter were the first to study the anatomy of the frontal sinuses using radiographic methods. ${ }^{7}$
The current study was designed to determine the reliability and Accuracy of frontal sinuses dimensions using MDCT as a method for sex estimation.

\section{Materials and Methods}

This is comparative retrospective study involving 100 Kashmiri adults (50 males and 50 females). They were referred to Government Medical College, Srinagar for CTPNS and CT- Head. Patients with age greater than 18 years were included and Patients with history of sinus pathologies such as development defects, chronic sinusistis, cysts, tumours were excluded from the study. Scans were performed using MDCT-16 slice configuration, Slice thicknesses of $3 \mathrm{~mm}$, with milli-Amperes (mAs) of 120 and $120 \mathrm{kV}$ were used.

The following measurements were obtained for both right and left sides. The maximum measurements were taken after going through different slices in coronal and axial sections then the averages of the right and left measurements were calculated using method used by sheriff et al in article.

Frontal Sinuses Measurements:

1. Point A- frontal sinus transverse length (width)

2. Point B- frontal sinus anteroposterior length (depth)

3. Point $\mathrm{C}$ - height of the frontal sinus

4. Point $\mathrm{D}$ - The distance between the highest points of the two sinuses

Point A and B were measured from Axial View and Point $\mathrm{C}$ and $\mathrm{D}$ were measured in Coronal view using Syngo fast view software. Data entered in Excel sheet. All the measurements were done by single experienced examiner and repeated over period of 1 week and mean of 2 measurements was taken. 


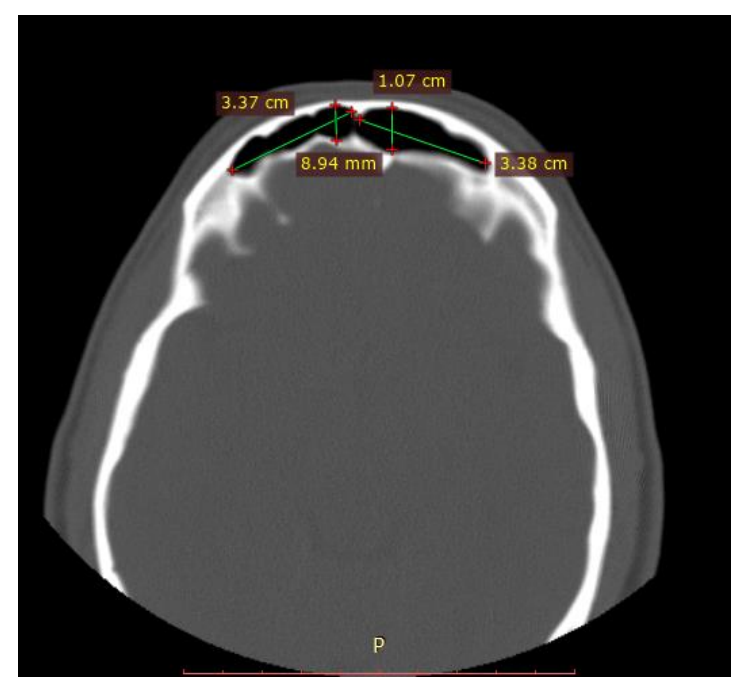

Fig. 1: Axial view of CT- SCAN used for measurement of point-A (width) and point-B (depth/ Anterioposterior distance)

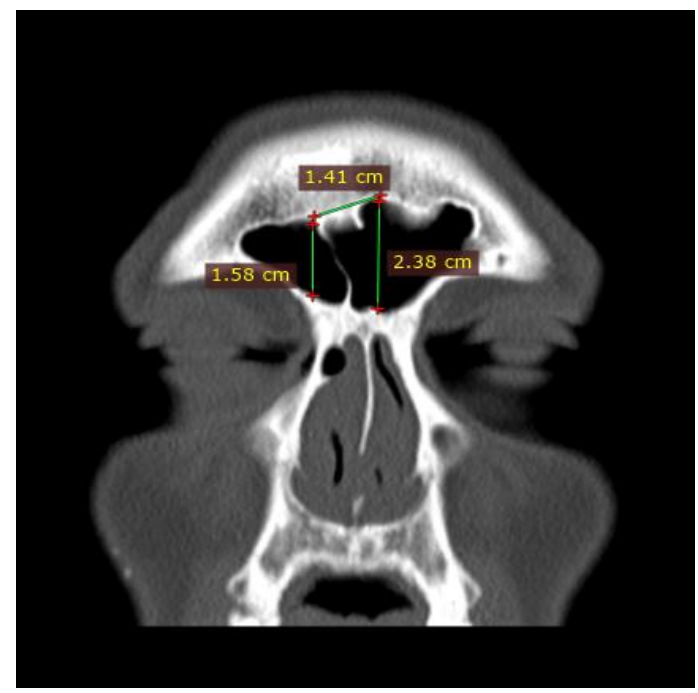

Fig. 2: Coronal view of CT-scan used for measurement of point $C$ (height) and point $D$ (distance between heights)

\section{Statistical Analysis}

Data were collected, coded and input to the statistical software IBM SPSS version 20.0. All data were subjected to descriptive and analytical statistics. All statistical analysis was done using two tailed t-tests and alpha error of 0.05 . $\mathrm{P}$ value less than or equal to 0.05 was considered to be statistically significant.

\section{Results}

As shown in table- 1 , in males the mean right width ranged from 13.500816 in females to 21.988039 in males, which was significantly larger in males.

Left width ranged from 12.345510 in females to 27.114510 in males, which was significantly larger in males.

Right depth ranged from 7.960408 in female and 8.185294 in males, which was not statistically significant.

Left depth ranged from 5.391429 in females to 9.441569 in males, which was significantly larger in males.

Right height ranged from 10.727959 in females to 14.594510 in males, which was statistically larger in males.

Left height ranged from 12.207551 in female to 16.829412 in males, which was significant.

Distance between heights in coronal plane ranged from 16.813469 in females to 16.519804 in males which was not significant.

Right depth, Right width, Left width, Left depth and Left height were significantly larger in males than in females. There was no significant difference in measurements of both sides in either males or females.

ROC analysis shows most discriminating variables was the left depth and left width average.

Cicchetti, gives the following quoted guidelines for interpretation of (intraclass coefficient) ICC measures:

1. Less than 0.40 (poor).

2. Between 0.40 and 0.59 (fair).

3. Between 0.60 and 0.74 (good).

4. Between 0.75 and 1.00 (excellent).

The analysis revealed that the stability of measurement was 0.660 in frontal sinuses parameter which is good.

Table 1: Showing mean values in male and female frontal sinuses with standard deviation

\begin{tabular}{|l|c|c|c|c|c|c|}
\hline Frontal Sinus & Female & & Male & & t & p-value \\
\hline & MEAN & SD & MEAN & SD & & \\
\hline Rt Width & 13.500816 & 7.3882491 & 21.988039 & 9.0682642 & -5.119 & 0.000 \\
\hline Lt width & 12.345510 & 8.8862495 & 27.114510 & 6.1867227 & -9.677 & 0.00 \\
\hline Rt Depth & 7.960408 & 4.9073032 & 8.185294 & 2.2660762 & -0.296 & 0.768 \\
\hline Lt Depth & 5.391429 & 1.8257864 & 9.441569 & 2.8569119 & -8.409 & 0.00 \\
\hline Rt Height & 10.727959 & 4.6519651 & 14.594510 & 3.7339407 & -4.593 & 0.00 \\
\hline Lt Height & 12.207551 & 7.8290497 & 16.829412 & 7.8009982 & -2.957 & 0.004 \\
\hline Distance & 16.813469 & 5.2225686 & 16.519804 & 6.1330356 & 0.257 & 0.797 \\
\hline
\end{tabular}




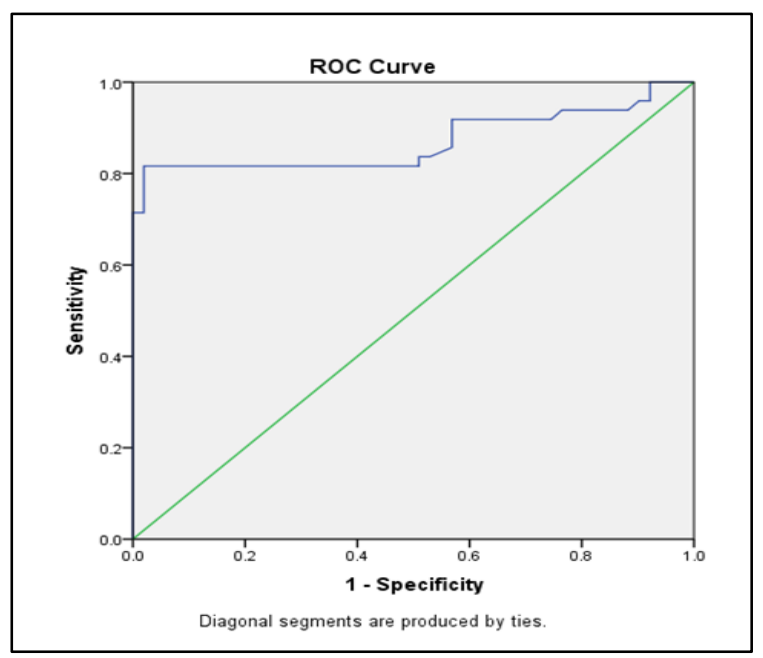

Fig. 3: Receiver operator character analysis (ROC) Left - depth average by sex area under the curve: 0.89

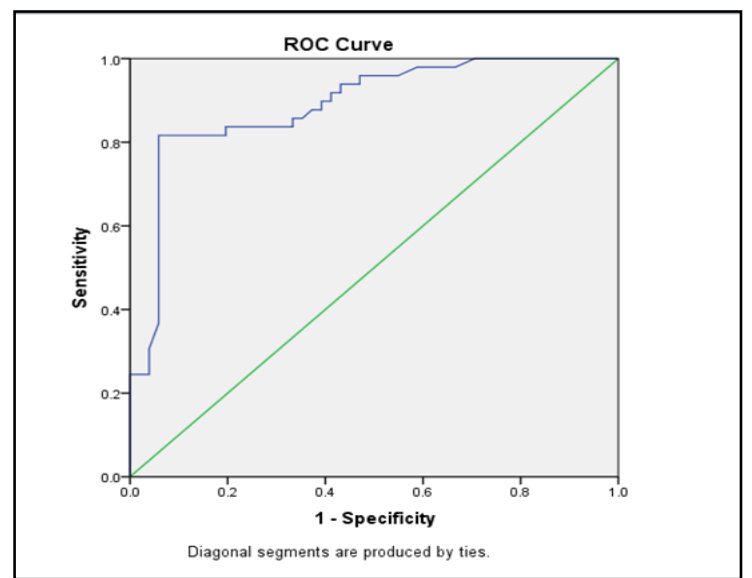

Fig. 4: ROC Left-Width average by sex area under the curve: $\mathbf{0 . 8 7 0}$

\section{Discussion}

The frontal sinus has become quite solidly in the literature as a safe method for comparative radio-graphic studies to get the identification. ${ }^{8}$ The frontal sinus is a hollow cavity located within the frontal bone. It develops during the fourth or fifth week of intrauterine life and grows until early adulthood by pneumatization. It contains two chambers which are typically asymmetrical because of the independent development of each sinus and they are separated by a bone septum. The human skull has been studied ante and post mortem for identification purposes both in anatomical and radiological assessments. Schuller was the first to establish the role of the frontal sinus for sex determination. ${ }^{9}$

Participants included in the present study were above 18 years old to exclude the possibility of incomplete growth which may lead to false results due to the fact that the frontal sinuses are absent at birth and fairly well developed between seventh and eighth year, only reaching their full size after puberty.
A study conducted by Hamed et al in 2014 concluded statistically higher values of FS height, transverse and Anterioposterior lengths for both right and left sides in males as compared to females. ${ }^{10}$ In our study the most discriminating variables were the left depth and left width.

Belaldavar, et al. conducted study on Indian population and he observed that the mean values of the frontal sinus height, width and area are greater in males. The mathematical model based on logistic regression analysis gives an average concordance index for sex determination of $64.6 \%$. Thus, frontal sinus provides average accuracy in sex determination among Indian population. This may be due to its greater variation in morphology. ${ }^{11}$

Taniguchi et al. in 2003 examined 24 cases for frontal sinuses Compared their of the ante and post mortem films which gave identical result in $75 \%$. It signifies usefulness of frontal sinuses uniqueness in human identification. ${ }^{12}$

Camargo et al in 2007 stated that the mean values of the frontal sinus were greater in males and the left area was larger than the right area, based on student's t-test at the 5\% level of significance. The mathematical model based on logistic regression analysis gave a concordance index for gender of $79.7 \%$ in the cases studied. ${ }^{13}$

Iordan and Ulmeanu, ${ }^{14}$ Falguera, ${ }^{15}$ Soriano et al., ${ }^{16}$ Silva et al. ${ }^{17}$ Tang et al., ${ }^{18}$ Carvalho et al. ${ }^{19}$ conducted various studies which showed uniqueness of frontal sinus in an individual, which was used for individual's identity verification.

Mathur et al. observed highly significant difference was observed in both width and height of frontal sinus between males and females. He concluded that the frontal sinus can be used as an auxiliary method in sex prediction. ${ }^{20}$

In 2013 an original research conducted by Navdeep et al showed no statistical significance was found between mean area of frontal sinus between males and females. The frontal sinus analysis is not reliable to assist sex discrimination. ${ }^{21}$

In the present study no significant difference was seen between right and left sides in both males and females. Statistically significant difference was seen in right width, left width, left depth, right and left height, whereas no significance was seen in right depth and distance between the maximum heights.

\section{Conclusion}

As far as the best of our knowledge, the present study was the first study in Kashmiri population for gender estimation using frontal sinus morphometric parameters. This study shows promising results in gender estimation and the most significant results were obtained with left width and left depth parameters. In present study small sample size was taken, further research should aim at involving larger samples which include varying geographic regions. So that data obtained can be used for forensic identification.

\section{Conflict of Interest: Nil.}




\section{References}

1. Wafaa M. Abdel Moneim, Randa H. Abdel Hady, Ragaa M Abdel Maaboud, Hala M. Fathy, and Ahmed Mostafa Hamed. "Identification of Sex Depending on Radiological Examination of Foot and Patella". Am J Forensic Med Pathol. 2008;29(2).

2. Kewal Krishan, Tanuj Kanchan, and Abhilasha Sharma. "Sex Determination from Hand and Foot Dimensions in a North Indian Population". J Forensic Sci. 2011;56(2).

3. Deshmukh AG \& Devershi DB. "Comparison of Cranial Sex Determination by Univariate and Multivariate Analysis". $J$ Anat Soc. 2006;55(2):48-51.

4. Tanuj Kanchan, Kewal Krishan. Personal Identification in Forensic Examinations. Kanchan and Krishan, Anthropol. 2013;2:1.

5. Ahmed, Azhar GH. CT scan images analysis of maxillary sinus dimensions as a forensic tool for sexual and racial detection in a sample of kurdish population". Eur Sci J. 2015;11(18).

6. Naima Abd El-Halim Sherifa, Abeer Abd El-Moneim Shetaa, Mohamed Eid Ibrahimb, Rania Abd El-Meguid Kakaa, Maii Farag Henaidya. "Evaluation of the paranasal sinuses dimensions in sex estimation among a sample of adult egyptians using multidetector computed tomography". $J$ Forensic Radiol Imaging. 2017;11:33-39.

7. Bhakti A. Soman, G. P. Sujatha, Ashok Lingappa. "Morphometric evaluation of the frontal sinus in relation to age and gender in subjects residing in Davangere, Karnataka". $J$ Forensic Dent Sci. 2016;8(1):57.

8. Thaís Aparecida Xavier, Andrea Sayuri Silveira Dias Terada, Ricardo Henrique Alvesda Silva N. "Forensic application of the frontal and maxillary sinuses: A literature review". $J$ Forensic Radiol Imaging. 2015;3:105-110

9. Ana-Gabriela Benghiac, Bonnie A. Thiel, Danisia Haba. Reliability of the frontal sinus index for sex determination using CBCT. Rom J Leg Med. 2015;23:275-278.

10. Sameera Sh. Hamed, Adel M. El-Badrawy, Sherif Abdel Fattah. Gender identification from frontal sinus using multidetector computed tomography. S. Sh. Hamedetal. J Forensic Radiol Imaging. 2014;2(3):117-120.

11. Chetan Belaldavar, Vijayalakshmi S. Kotrashetti1, Seema R. Hallikerimath, Alka D. Kale. "Assessment of frontal sinus dimensions to determine sexual dimorphism among Indian adults". J Forensic Dent Sci. 2014;6(1)

12. M. Taniguchi, S Sakoda, T Kano, BLZhu, YK Amikodai, MQ Fujita et al., Possible use of nasal septum and frontal sinus patterns to radiographic identification of unknown human remains. Osaka City Med J. 2003;49:31-38.
13. JR Camargo, E Daruge, FB Prado, PHF Caria, MC Alves, RF Silva, et al., The frontal sinus morphology in radiographs of Brazilian subjects: its forensic importance. Braz J Morphol Sci. 2007;24(4)239-243.

14. A Iordan, D. Ulmeanu, Morphometric vectorial method of analysis of the frontal sinuses. Morphologie. 2008;92(296):710.

15. JR. Falguera, Reconhecimentosemi automáticode sinusfrontaispara identifi-cação humana for ensebaseadona TransformadaImagem-Florestaeno Con- textoda Forma [dissertação], Universidade Estadual Paulista, Institutode Biociências, Letrase Ciências Exatas, Bauru, 2008.

16. EP Soriano, MVD Carvalho, FB Santos, RIC Campello, CC. Mendoza, Aradiologia no processode identificação odontolegal, Rev. ABONac. 2008;16(3):180-184.

17. RF Silva, RN Pinto, GM Ferreira, E. Daruge Júnior, Importânciadas radiografias de seiofrontalparaaidentificação humana, Rev Bras Otorrinolaringol. 74(5) (2008)798.

18. JP Tang, DY Hu, FH Jiang, XJ. Yu, Assessing forensic applications of the frontal sinus in a Chinese Han population. Forensic Sci Int. 2009;183(1-3):104.

19. CARVALHO, Suzana Papile Maciel; SILVA, Ricardo Henrique Alves da; LOPES-JUNIOR, César, PERES, Arsenio Sales. Use of images for human identification in forensic dentistry. Radiol Bras. 2009;42(2):125-130.

20. H Mathur, A Mathur, J Ahmed, MK horate, P. Tripathi, Conventional frontal sinus imaging in identification of sex : original study in population of Udaipur City, India. J Med Sci Clin Res. 2013;1(1):33-37.

21. K Navdeep, C Sunira, D Parvathi, RM Srinivasa, T Neeraj, S Ruhi. The forensic importance of frontal sinus in gender discrimination: a morphometric study. J Oral Sign. 2013;5(1):2-5.

How to cite this article: Chalkoo A. H, Sharma P, Nazir N, Tariq S. Evaluation of the frontal sinuses dimensions in sex estimation among a sample of adult Kashmiri population using multidetector computed tomography. Int J Maxillofac Imaging. 2018;4(4):122125. 